\title{
Avaliação do nível de ruído em marcenarias no Distrito Federal, Brasil ${ }^{1}$
}

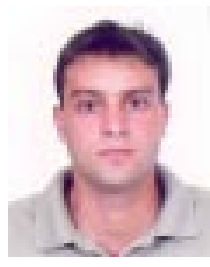

Fábio Venturoli ${ }^{2}$, Nilton C. Fiedler ${ }^{3}$, Luciano J. Minetti ${ }^{4} \&$ Ildeu S. Martins ${ }^{3}$

1 Trabalho de pesquisa financiado pelo CNPq e CAPES
2 NOVACAP. E-mail: venturoli@rudah.com.br (Foto)
${ }^{3}$ Depto. Engenharia Florestal/UnB. Fone: (61) 307-2700. E-mail: fiedler@unb.br
${ }^{4}$ Depto. Engenharia Florestal/UFV. Fone: (31) 3899-2721. E-mail: minetti@ufv.br

Protocolo 61 - 14/4/2003 - Aprovado em 15/10/2003

Resumo: Esta pesquisa foi realizada em marcenarias no Distrito Federal, com o objetivo de se avaliar e comparar, estatisticamente, o nível de ruído emitido pelas máquinas utilizadas na fabricação de móveis em 4 empresas. A avaliação foi feita com auxílio de um decibelímetro posicionado próximo ao ouvido do trabalhador enquanto ele operava determinada máquina, conforme preceitua a NR15. Foram avaliadas 6 máquinas, serra circular, tupia, desempenadeira, desengrossadeira, furadeira horizontal e lixadeira de cinta. A análise estatística foi realizada com o uso de um modelo fatorial e teste de médias. Os resultados indicaram diferença significativa a $5 \%$ de probabilidade entre todas as máquinas, nessas empresas. O ruído médio encontrado foi de 92,16 $\mathrm{dB}(\mathrm{A})$ e o maior valor foi encontrado na serra circular na empresa 4 (101 dB(A)). A furadeira horizontal foi a única máquina, em todas as empresas, que se enquadrou dentro do limite permitido na NR15, que é de $85 \mathrm{~dB}(\mathrm{~A})$ para uma jornada de trabalho de 8 horas diárias. As demais máquinas apresentaram problemas quanto à emissão de ruído.

Palavras-chave: fatores ambientais, ergonomia

\section{Evaluation of the noise level in carpentries in the Federal District, Brazil}

\begin{abstract}
This research was carried out in a carpentry in the Federal District, Brazil, with the objective to evaluate and to compare the noise level emitted by the machines used in the manufacture of furniture in four establishments. The evaluation was made with the one noise level measured and it was located as to ear of the worker while operating the machine as per NR15 norm. Six machines were evaluated. The statistical analysis was done using factorial design and mean test. The results indicated significant differences at $5 \%$ probability level among machines in the four companies. The mean noise level was of $92,16 \mathrm{~dB}(\mathrm{~A})$. The highest value was found in the buzz saw in company $4(101 \mathrm{~dB}(\mathrm{~A}))$. The horizontal wimble was the only machine in all the companies that fitted with in the limits allowed in the NR15 norm (85 dB(A)) for a daily working of 8 hours. The other machines presented problems related to the noise emission.
\end{abstract}

Key words: environmental factors, ergonomics

\section{INTRODUÇÃO}

As indústrias de fabricação de móveis de madeira (marcenarias) no Distrito Federal ocupam o sexto lugar quanto ao número de estabelecimentos comerciais, correspondendo a aproximadamente 300 empresas. No que se refere à mão-deobra empregada, a atividade ocupa o oitavo lugar, com um total aproximado de 2.500 empregados (SINDIMAM, 1993).

Os trabalhadores em marcenarias, de maneira geral, estão expostos a diversos riscos para a sua integridade física e psicológica. Existe um elevado risco de acidentes, podendo levar ao afastamento do trabalhador por períodos de tempo consideráveis, o que, além de prejudicar o funcionário, implica em prejuízos para as empresas, em virtude de, na maioria das vezes, não haver mão-de-obra treinada para substituir o acidentado, interferindo, assim, nos prazos de entrega dos produtos e levando conseqüentemente ao afastamento da clientela (Fiedler et al., 2001). Uma visão do ambiente de trabalho facilita a compreensão das dificuldades, desconfortos, insatisfações e a ocorrência de acidentes e doenças ocupacionais (Grandjean, 1982).

No Brasil, o Ministério do Trabalho e Emprego, baseado em estudos específicos, normatiza índices que possibilitam executar o trabalho com maior conforto e segurança propiciando maior saúde, satisfação, qualidade e eficiência ao trabalhador. As penalidades para as empresas que não se adequam a essas 
normas vão desde a interdição até ao fechamento da empresa, além do pagamento de multas (Brasil, 1998).

$\mathrm{Na}$ maioria das vezes, quando se compara o ambiente de trabalho, das marcenarias, com as Normas Regulamentadoras do Ministério do Trabalho e Emprego, verifica-se que em muitos casos existem diversas inadequações podendo afetar muito a saúde e a segurança do trabalhador. A falta de informação dos funcionários e dos proprietários, as necessidades constantes de aumento de produtividade e de redução de custos e as rápidas e constantes mudanças na Legislação são as principais causas da falta de adequação às normas (Silva, 1999).

Fisicamente, o ruído é definido como um som ou um complexo de sons indesejáveis, que causam incômodo e neuroses agudas. Afeta, física e psicologicamente, o ser humano e, dependendo dos níveis, causa lesões auditivas irreversíveis no trabalhador, podendo levar à surdez permanente (PMAC, 1994). Ruídos intensos tendem a prejudicar a concentração mental e certas tarefas que exigem atenção ou velocidade e precisão de movimentos (Minetti et al., 1998).

Considerando-se os prejuízos que o ruído causa às pessoas expostas a ele, faz-se necessário tomar medidas no sentido de se reduzir o máximo possível as intensidades da pressão sonora nos ambientes de trabalho. A maneira mais freqüente de se solucionar o problema, é o fornecimento de protetores auriculares para os trabalhadores (Vieira, 1997). No entanto, o mais correto é atuar no ambiente de trabalho reduzindo o nível de ruído na fonte, como forma preventiva.

Para ruídos de até $85 \mathrm{~dB}(\mathrm{~A})$, segundo a norma brasileira, o trabalhador pode se expor durante toda a jornada de trabalho diária (8 horas); contudo, acima desse nível começam a surgir riscos para os trabalhadores (Segurança e Medicina do Trabalho, 1996). Os ruídos intensos, acima de $90 \mathrm{~dB}(\mathrm{~A})$, dificultam a comunicação verbal, as pessoas precisam falar mais alto e prestar mais atenção para serem compreendidas, aumentando a tensão psicológica (Iida, 1990).

Estudos têm mostrado que a introdução de uma música de fundo, principalmente em situações de trabalho altamente repetitivo, tem sido recomendada para quebrar a monotonia do ambiente e reduzir a fadiga. A música melhora a atenção e a vigilância, produzindo sensação de bem-estar mas, se tocada continuamente, perde o efeito estimulador; ela deve ser tocada durante uma parte da jornada de trabalho, de preferência nos horários em que a fadiga se manifesta mais intensa, e não é a música em si, nem o tipo, mas a mudança que ela provoca no ambiente, que influi no desempenho (Iida, 1990). Os tempos de exposição aos níveis de ruído não devem exceder os limites de tolerância apresentados na Norma Regulamentadora NR 15, anexo 1 (Segurança e Medicina do Trabalho, 1996).

Esta pesquisa teve como objetivo de se avaliar e comparar estatisticamente o nível de ruído emitido pelas máquinas na fabricação de móveis em marcenarias no Distrito Federal.

\section{MATERIAL E MÉTODOS}

\section{Região de estudo}

O estudo foi desenvolvido em 4 marcenarias (empresas fabricantes de móveis a partir de madeiras) na cidade de Brasília, DF entre o mês de julho de 2001 e julho de 2002. As empresas foram escolhidas aleatoriamente a partir de um diagnóstico feito junto à Secretaria da Fazenda do Governo do Distrito Federal, Sindicato das Indústrias de Madeira e do Mobiliário do Distrito Federal (SINDIMAM) e Federação das Indústrias de Brasília (FIBRA). Este levantamento permitiu detectar o número de empresas existentes, a razão social e a localização de cada uma.

\section{População, amostragem e modelo estatístico}

As avaliações do nível de ruído emitido pelas máquinas, foram realizadas por um estudo de caso em que foram consideradas, entre as empresas, 6 máquinas, em estado normal de funcionamento, comuns a todas as empresas e por serem as principais máquinas envolvidas no processo de fabricação de móveis, as quais foram: a serra circular de carrinho, a tupia de mesa, a desempenadeira, a desengrossadeira, a furadeira horizontal e a lixadeira de cinta, caracterizadas de acordo com SENAI (1987), conforme mostra a Tabela 1.

Para a avaliação do nível de ruído considerou-se um modelo fatorial inteiramente ao acaso, com 2 fatores, sendo eles máquinas com 6 níveis e empresas com 4 níveis e diferentes números de repetições, segundo o seguinte modelo estatístico (Searle, 1971; Neter \& Wasserman, 1974):

Tabela 1. Descrição técnica das máquinas avaliadas

\begin{tabular}{ll}
\hline \multicolumn{1}{c}{ Máquina } & \multicolumn{1}{c}{ Descrição } \\
\hline $\begin{array}{l}\text { Serra circular } \\
\text { de carrinho }\end{array}$ & $\begin{array}{l}\text { Utilizada para serrar madeira ou derivados em corte reto, por meio de uma serra circular dentada acoplada a uma } \\
\text { mesa de corpo fixo e um carrinho para movimentar a peça a ser cortada } \\
\text { Utilizada para fazer molduras, rebaixamentos, ranhuras, perfis e canais. Composta de uma base de ferro na qual se } \\
\text { apóia um tampo e em cujo centro se encontra um eixo onde se prendem as ferramentas de corte, que giram na alta } \\
\text { velocidade de 4000 a } 8000 \text { rotações min }{ }^{-1}\end{array}$ \\
Desempenadeira & $\begin{array}{l}\text { Utilizada para nivelar a superfície da peça } \\
\text { Visa dimensionar a espessura das peças. Utilizada também na operação de desbaste, para aplainar superfícies, } \\
\text { tornando-as uniformes. É constituída por uma base de ferro fundido e possui, na parte superior, uma capa de } \\
\text { proteção cobrindo o eixo, o qual é constituído por navalhas e dois rolos de alimentação que funcionam } \\
\text { automaticamente. Ao nível da mesa estão dispostos outros dois rolos lisos que servem para o deslize da madeira }\end{array}$ \\
Furadeira horizontal & $\begin{array}{l}\text { Utilizada para fazer furos e cavas em peças de madeira e encaixes de espigas ou cavilhas } \\
\text { Acabamento de superfícies planas ou curvas. Elimina imperfeições e asperezas para que a peça possa receber o } \\
\text { acabamento final. Compõe-se de duas colunas ligadas por uma cinta de lixa, entre as quais existe uma mesa fixa } \\
\text { onde é apoiada a peça de madeira }\end{array}$ \\
\hline
\end{tabular}

Fonte: SENAI (1987) 


$$
Y_{i j k}=\mu+a_{i}+b_{j}+\left(a x b_{i j}\right)+e_{i j k}
$$

donde:

$\mathrm{Y}_{\mathrm{ijk}}$ - observação referente à máquina i na empresa $\mathrm{j}$

$\mu$ - média geral

$\mathrm{a}_{\mathrm{i}} \quad$ - efeito da máquina i (fixo)

$\mathrm{b}_{\mathrm{j}} \quad$ - efeito da empresa $\mathrm{j}$ (fixo)

$(\mathrm{axb})_{\mathrm{ij}}$ - efeito da interação máquina e empresa (fixo)

$\mathrm{e}_{\mathrm{ijk}} \quad$ - erro aleatório ou resíduo

As médias foram comparadas pelo teste de StudentNewman-Keuls a 5\% de probabilidade.

O ruído das máquinas foi medido com um decibelímetro digital modelo SL-4001 da marca Lutron, com sensor posicionado próximo ao nível do ouvido do trabalhador, enquanto ele operava a máquina, conforme preceitua a Norma Regulamentadora NR15 (Segurança e Medicina do Trabalho, 1996); os dados foram coletados em intervalo de 5 min durante toda a jornada de trabalho, sendo os valores de decibéis $(\mathrm{dB}(\mathrm{A}))$ lidos e anotados.

\section{RESULTADOS E DISCUSSÃO}

O nível de ruído médio encontrado nas empresas foi de $92,16 \mathrm{~dB}(\mathrm{~A})$; os resultados da análise de variância para o nível de ruído são apresentados na Tabela 2 .

Tabela 2. Resultados da análise de variância para o nível de ruído emitido pelas máquinas nas empresas analisadas

\begin{tabular}{lrrrr}
\multicolumn{1}{c}{ FV } & GL & \multicolumn{1}{c}{ SQ } & \multicolumn{1}{c}{ QM } & \multicolumn{1}{c}{ F } \\
\hline Empresa & 3 & 74,17 & 24,72 & 1,777 \\
Máquina & 5 & 9563,02 & 1912,60 & $137,434^{* *}$ \\
Empresa x máquina & 15 & 1561,90 & 104,12 & $7,482^{* *}$ \\
Resíduo & 373 & 5190,87 & 13,92 & \\
Total & 396 & 15842,41 & 2154,11 & \\
\hline
\end{tabular}

** Significativo ao nível de $1 \%$ de probabilidade

Verificou-se interação significativa entre máquinas e empresas, indicando que o comportamento de um fator depende dos níveis do outro. Este fato evidenciou uma dependência entre as máquinas e empresas e, neste caso, foi necessário um desdobramento da interação, para avaliar o comportamento de cada máquina em cada empresa.

Os resultados referentes à similaridade entre as empresas eram esperados, pois no caso do nível de ruído, segundo Iida (1990), o ambiente físico tem menor influência sobre o funcionamento da máquina.

Em função das grandes diferenças existentes entre as máquinas envolvidas no processo de fabricação de móveis, principalmente com relação à função desempenhada, era de se esperar que existisse diferença significativa entre as máquinas estudadas.

\section{Desdobramento da interação (estudo de máquinas dentro das empresas)}

Para decomposição da interação máquina x empresa, fez-se uma análise de variância para analisar o efeito do fator máquina dentro do fator empresa, conforme a Tabela 3.
Tabela 3 Resultado da análise de variância para o estudo das máquinas dentro das empresas

\begin{tabular}{lrrrc}
\multicolumn{1}{c}{ FV } & GL & \multicolumn{1}{c}{ SQ } & \multicolumn{1}{c}{ QM } & \multicolumn{1}{c}{ F } \\
\hline Empresa & 3 & 74,17 & 24,72 & 1,77 \\
Maq./Empr.1 & 5 & 1360,56 & 272,11 & $16,199 * *$ \\
Maq./Empr.2 & 5 & 2583,70 & 516,74 & $86,357 * *$ \\
Maq./Empr.3 & 5 & 2372,07 & 474,41 & $47,490 * *$ \\
Maq./Empr.4 & 5 & 4261,04 & 852,21 & $32,933 * *$ \\
Resíduo & 373 & 5190,87 & 13,92 & \\
Total & 396 & 15842,41 & 2154,11 & \\
\hline
\end{tabular}

** Significativo ao nível de $1 \%$ de probabilidade

De acordo com os resultados apresentados na Tabela 3, observou-se diferença significativa entre as máquinas nas 4 empresas; assim, foi necessária a utilização de um teste de comparações de médias para avaliação das similaridades e das diferenças existentes entre elas.

Os resultados do teste de Student-Newman-Keuls para o nível de ruído nas 4 empresas, são apresentados na Tabela 4, que mostra também os limites máximos de exposição dos trabalhadores ao ruído nas diferentes máquinas, de acordo com os valores médios.

Tabela 4. Resultados do teste de comparações de médias de Student-Nweman-Keuls para o nível de ruído das máquinas nas empresas estudadas

\begin{tabular}{|c|c|c|c|}
\hline Empresa & Máquina & $\begin{array}{l}\text { Média } \\
\mathrm{dB}(\mathrm{A})^{*}\end{array}$ & $\begin{array}{l}\text { Max. Exposição } \\
\text { Diária Permitida }\end{array}$ \\
\hline \multirow{6}{*}{1} & Desempenadeira & $94,88 \mathrm{a}$ & 2 horas \\
\hline & Tupia de mesa & $93,15 \mathrm{ab}$ & 2 horas e $40 \mathrm{~min}$ \\
\hline & Serra circular de carrinho & $93,09 \mathrm{ab}$ & 2 horas e $40 \mathrm{~min}$ \\
\hline & Desengrossadeira & $92,43 \mathrm{ab}$ & 3 horas \\
\hline & Lixadeira de cinta & $89,55 b$ & 4 horas e $30 \mathrm{~min}$ \\
\hline & Furadeira horizontal & $84,53 \mathrm{c}$ & 8 horas \\
\hline \multirow{6}{*}{2} & Serra circular de carrinho & $97,16 \mathrm{a}$ & 1 hora e $30 \mathrm{~min}$ \\
\hline & Tupia de mesa & $96,24 \mathrm{ab}$ & 1 hora e $45 \mathrm{~min}$ \\
\hline & Desengrossadeira & $94,41 b c$ & 2 horas e $15 \mathrm{~min}$ \\
\hline & Desempenadeira & $93,55 \mathrm{c}$ & 2 horas e $40 \mathrm{~min}$ \\
\hline & Lixadeira de cinta & $84,57 d$ & 8 horas \\
\hline & Furadeira horizontal & $84,18 d$ & 8 horas \\
\hline \multirow{6}{*}{3} & Serra circular de carrinho & $98,06 \mathrm{a}$ & 1 hora e $15 \mathrm{~min}$ \\
\hline & Desempenadeira & $96,28 \mathrm{a}$ & 1 hora e $45 \mathrm{~min}$ \\
\hline & Desengrossadeira & $92,74 b$ & 3 horas \\
\hline & Tupia de mesa & $92,55 b$ & 3 horas \\
\hline & Lixadeira de cinta & $88,55 \mathrm{c}$ & 8 horas \\
\hline & Furadeira horizontal & $80,75 d$ & 8 horas \\
\hline \multirow{6}{*}{4} & Serra circular de carrinho & $101,34 \mathrm{a}$ & 1 hora \\
\hline & Desengrossadeira & $98,77 \mathrm{ab}$ & 1 hora e $15 \mathrm{~min}$ \\
\hline & Desempenadeira & $95,34 \mathrm{ab}$ & 2 horas \\
\hline & Tupia de mesa & $94,17 b$ & 2 horas e $15 \mathrm{~min}$ \\
\hline & Lixadeira de cinta & $85,15 \mathrm{c}$ & 8 horas \\
\hline & Furadeira horizontal & $80,32 c$ & 8 horas \\
\hline
\end{tabular}

* Médias seguidas de letras iguais não diferem estatisticamente ao nível de $5 \%$ de probabilidade. Resultados expressos por empresa

O teste de comparação de médias serviu para mostrar diferenças estatísticas entre as máquinas e empresas e verificar que os níveis de ruído emitidos pelas máquinas podem não diferir estatisticamente, mesmo que as máquinas sejam diferentes em marcas, modelos e rotação do motor.

A análise da Tabela 4 permitiu afirmar-se que na Empresa 1 a máquina de maior emissão de ruído foi a desempenadeira, 
que não diferiu estatisticamente da tupia de mesa, da serra circular de carrinho nem da desengrossadeira; estas não diferiram estatisticamente da lixadeira de cinta; já a furadeira horizontal, máquina com menor emissão de ruído, diferiu estatisticamente de todas as demais máquinas e foi a única que não ultrapassou o limite de $85 \mathrm{~dB}(\mathrm{~A})$ permitido pela legislação trabalhista brasileira para uma jornada de trabalho contínua de 8 horas diárias. As demais máquinas devem ser motivo de preocupação por parte dos responsáveis pela empresa, devendo estes atentarem para a exigência do uso de protetores auriculares pelos trabalhadores.

Ainda de acordo com a Tabela 4, na Empresa 2 observou-se que a serra circular de carrinho, máquina com maior emissão de ruído, não diferiu estatisticamente da tupia de mesa. A tupia de mesa e a desengrossadeira não apresentaram níveis de ruído diferentes estatisticamente, mas sim diferenças estatísticas com relação à serra circular de carrinho. A desengrossadeira não foi diferente estatisticamente da desempenadeira. Estas foram estatisticamente diferentes da serra circular de carrinho e da tupia de mesa. A lixadeira de cinta e a furadeira horizontal não diferiram estatisticamente, sendo diferentes das demais máquinas, porém apresentaram os menores índices.

Nesta empresa todas as máquinas, exceto a lixadeira de cinta e a furadeira, excederam o limite máximo permitido pela legislação trabalhista brasileira (NR15) que é de $85 \mathrm{~dB}(\mathrm{~A})$, devendo o trabalho nessas máquinas ser executado obrigatoriamente com a utilização de protetores auriculares; já na empresa 3 o teste de Student-Newman-Keuls (Tabela 4), indicou que a serra circular de carrinho e a desempenadeira não diferiram estatisticamente na emissão de ruído, o mesmo ocorrendo em relação às desengrossadeira e tupia de mesa, enquanto a lixadeira de cinta e a furadeira horizontal diferiram de todas as outras máquinas.

Os maiores níveis de ruído foram encontrados na desempenadeira e na serra circular de carrinho e o menor na furadeira horizontal.

Nesta empresa somente a furadeira horizontal não apresentou níveis de ruído acima de $85 \mathrm{~dB}$ (A) devendo as demais máquinas serem utilizadas com o uso de protetores auriculares como medida corretiva, sendo o ideal a redução do ruído na fonte.

$\mathrm{Na}$ Empresa 4 a serra circular de carrinho, a desengrossadeira e a desempenadeira não diferiram estatisticamente, enquanto a desengrossadeira e a desempenadeira não diferiram estatisticamente da tupia de mesa mas, sim, das demais máquinas. A lixadeira de cinta e a furadeira horizontal não diferiram estatisticamente.

Nesta empresa, a lixadeira de cinta e a furadeira horizontal não ultrapassaram o limite de $85 \mathrm{~dB}(\mathrm{~A})$; já a serra circular de carrinho apresentou o nível de ruído mais alto entre todas as máquinas de todas as empresas, $101 \mathrm{~dB}(\mathrm{~A})$, cujo índice coloca o operador dessa máquina em situação delicada pois o limite de tempo de operação é de no máximo 1 hora para a jornada de trabalho de 8 horas diárias, sem a utilização de protetores auriculares.

\section{Análise comparativa do nível de ruído nos postos de trabalho}

Os dados dos níveis de ruído nas diferentes máquinas e empresas foram suficientes para demonstrar que não existiu diferença significativa entre as empresas e, sim, entre as máquinas nas empresas. $O$ fato mais evidente foi que não existiu um padrão entre as empresas, pois não se constatou nenhuma combinação entre o ruído emitido pelas máquinas e as empresas, com exceção da lixadeira de cinta e da furadeira horizontal, que em todos os casos apareceram com as menores emissões de ruído e de maneira geral não diferiram estatisticamente. Assim, pode-se afirmar que as máquinas são independentes, o que ressalta a importância de estudá-las separadamente.

Com relação à Norma Regulamentadora do Ministério do Trabalho e Emprego (NR 15), os níveis de ruído encontrados em $83 \%$ das máquinas estavam em desacordo com a referida norma necessitando, portanto, da adoção de medidas para a redução do nível de ruído na fonte ou como mediada corretiva, o uso obrigatório de protetores auriculares.

Níveis de ruído muito elevados, além de sérios danos ao sistema auditivo dos trabalhadores, podem causar acidentes e afetar a produção, uma vez que os alarmes e outros sinais de orientação dentro da empresa não são ouvidos, afetando assim a comunicação, que é muito importante dentro de uma indústria. Uma forma de se reduzir o ruído é fechar totalmente a máquina ou as partes da máquina que são particularmente barulhentas. Se o ruído não puder ser reduzido na fonte, pode-se isolar a(s) máquina(s) barulhenta(s), mantendo-a(s) longe dos locais onde o trabalho é de fato realizado; uma outra medida seria analisarse, durante a substituição das máquinas, esses níveis e optar por modelos com fontes menos ruidosas. A manutenção periódica das máquinas também ajuda na diminuição dos níveis de ruído.

A furadeira horizontal foi a única máquina, em todas as empresas, que se enquadrou dentro do limite permitido pela legislação trabalhista brasileira (NR15) que é de $85 \mathrm{~dB}(\mathrm{~A})$ para uma jornada de trabalho de 8 horas diárias.

Deve-se levar em consideração que o nível de ruído sofre variações conforme o tipo de peça utilizada (madeira maciça ou chapas), tipo de corte realizado na peça (longitudinal, radial ou transversal) e também de acordo com a manutenção da máquina, estado de conservação, modelo e marca.

\section{CONCLUSÕES}

1. Todas as máquinas, exceto a lixadeira de cinta e a furadeira horizontal, apresentaram níveis de ruído acima do permitido pela NR 15 que é de $85 \mathrm{~dB}(\mathrm{~A})$.

2. A máquina mais problemática com relação ao nível de ruído, foi a serra circular de carrinho na Empresa 4 (101,3dB(A)), de acordo com a norma citada acima.

3. A máxima exposição diária permitida para a serra circular de carrinho é de 1 hora durante toda a jornada de trabalho, de 8 horas diárias.

\section{LITERATURA CITADA}

Brasil. Consolidação das leis do trabalho. - 23. ed. Atual. e aum. - São Paulo: Saraiva, 1998. 193p. Legislação brasileira 
Fiedler, N.C.; Venturoli, F.; Minetti, L.J.; Vale, A.T. Diagnóstico de fatores humanos e condições de trabalho em marcenarias do Distrito Federal. Revista Floresta, Brasília, v.31, n.1 e 2, p.105-113, 2001.

Grandjean, E. Fitting the task to the man - an ergonomic approach. London: Taylor \& Francis, 1982. 379p.

Iida, I. Ergonomia; projeto e produção. São Paulo: Edgard Blucher, 1990. 465p.

Minetti, L.J.; Souza, A.P.; Machado, C.C.; Fiedler, N.C.; Baêta, F.C. Avaliação dos efeitos do ruído e da vibração no corte florestal com motosserra. Revista Árvore, Viçosa, v.22, n.3, p.325-330, 1998

Neter, J.; Wasserman, W. Applied linear statistical models. Homewood: Richard D. Irwin, Inc. 1974. 842p.

PMAC Exposição ao ruído; norma para a proteção de trabalhadores que trabalham em atividades com barulho. Revista Proteção, Rio de Janeiro, v.6, n.29, p.136-138, 1994.
Searle, S. R. Linear models. New York: John Wiley \& Sons, Inc. 1971.543p.

Segurança e Medicina do Trabalho. 30. ed. São Paulo: Atlas, 1996. 499p. Manuais de Legislação Atlas, 16

SENAI - Serviço Nacional de Aprendizagem Industrial. Curso sobre fabricação de móveis. Belo Horizonte: Serviço Nacional de Aprendizagem Industrial. 1987. Módulos de curso não paginados

Silva, K.R. Análise de fatores ergonômicos em marcenarias do município de Viçosa - MG. Viçosa: UFV, 1999. 97p. Dissertação Mestrado

SINDIMAM - Diagnóstico das indústrias da madeira e do mobiliário do Distrito Federal. Relatório final, IEL/DF. julho de 1993. s.p.

Vieira, S.D.G. Análise ergonômica do trabalho em uma empresa de fabricação de móveis tubulares. Estudo de caso. Florianópolis: UFSC, 1997. Dissertação Mestrado 